\title{
Delayed chilling appears to counteract flowering advances of apricot in southern UK
}

Article

Accepted Version

Creative Commons: Attribution-Noncommercial-No Derivative Works 4.0

Martinez-Luscher, J., Hadley, P., Ordidge, M., Xu, X. and Luedeling, E. (2017) Delayed chilling appears to counteract flowering advances of apricot in southern UK. Agricultural and Forest Meteorology, 237-238. pp. 209-218. ISSN 0168-1923 doi: https://doi.org/10.1016/j.agrformet.2017.02.017 Available at https://centaur.reading.ac.uk/69256/

It is advisable to refer to the publisher's version if you intend to cite from the work. See Guidance on citing.

To link to this article DOI: http://dx.doi.org/10.1016/j.agrformet.2017.02.017

Publisher: Elsevier

All outputs in CentAUR are protected by Intellectual Property Rights law, including copyright law. Copyright and IPR is retained by the creators or other copyright holders. Terms and conditions for use of this material are defined in the End User Agreement.

www.reading.ac.uk/centaur 
Central Archive at the University of Reading

Reading's research outputs online 


\section{Delayed chilling appears to counteract flowering advances}

\section{of apricot in southern UK}

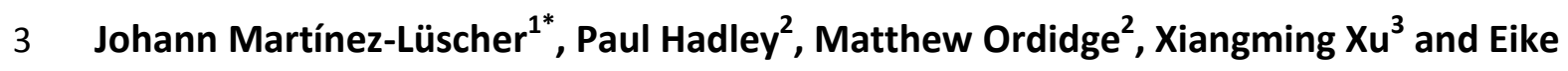

$4 \quad$ Luedeling ${ }^{4,5}$

$5 \quad{ }^{1}$ Oakville Experiment Station, Department of Viticulture and Enology, University of California Davis

6 Oakville, California 94562, USA

$7{ }^{2}$ Centre for Horticulture, School of Agriculture, Policy and Development, University of Reading,

8 Whiteknights, Reading, RG6 6AR, UK

$9{ }^{3}$ Genetics and Crop Improvement Programme, East Malling Research, New Road, East Malling ME19

$106 \mathrm{BJ}, \mathrm{UK}$

$11{ }^{4}$ World Agroforestry Centre, Nairobi 00100, Kenya

$12{ }^{5}$ Centre for Development Research (ZEF), University of Bonn, Bonn 53113, Germany

*Corresponding author:

14 Dr. Johann Martínez-Lüscher

15 jmluscher@gmail

16 Genetics and Crop Improvement, East Malling Research

17 New Road, East Malling. ME19 6BJ, UK

18 Tel: $(+44)(0) 1732843833$

19 Fax: $(+44)(0) 1732849067$ 


\section{Abstract}

21 Temperatures are rising across the globe, and the UK is no exception. Spring phenology of perennial

22 fruit crops is to a large extent determined by temperature during effective chilling (endo-dormancy) and heat accumulation (eco-dormancy) periods. We used the apricot flowering records of the UK National Fruit Collections (NFC) to determine the influence of temperature trends over recent decades (1960 to 2014) on apricot (Prunus armeniaca L.) flowering time. Using Partial Least Squares (PLS) regression, we determined the respective periods for calculating chill and heat accumulation. Results suggested intervals between September $27^{\text {th }}$ and February $26^{\text {th }}$ and between December $31^{\text {st }}$ and April $12^{\text {th }}$ as the effective chilling and warming periods, respectively. Flowering time was correlated with temperature during both periods, with warming during chilling corresponding to flowering delays by $4.82 \mathrm{~d}^{\circ} \mathrm{C}^{-1}$, while warming during heat accumulation was associated with bloom advances by $9.85 \mathrm{~d}^{\circ} \mathrm{C}^{-1}$. Heat accumulation started after accumulating $62.7 \pm 5.6$ Chill Portions, and flowering occurred after a further $3744 \pm 1538$ Growing Degree Hours (above a base temperature of $4^{\circ} \mathrm{C}$, with optimal growth at $26^{\circ} \mathrm{C}$ ). When examining the time series, the increase in temperature during the chilling period did not appear to decrease overall chill accumulation during the chilling period but to delay the onset of chill accumulation and the completion of the average chill accumulation necessary to start heat accumulation. The resulting delay in heat responsiveness appeared to weaken the phenology-advancing effect of spring warming. These processes may explain why apricot flowering time remained relatively unchanged despite significant temperature increases. A consequence of this may be a reduction of frost risk for early flowering crops such as apricot in the UK. regression 


\section{Introduction}

Phenological records provide valuable data for characterizing the effect of variation in environmental conditions on plant development. Frequently, these records cover a longer time span than any defined experiment, making them one of the most valuable pieces of evidence of the impacts of global warming over past decades or even centuries (Fitchett et al., 2015; Menzel et al., 2008). Flowering time of fruit crops is one of the most widely used indicators of climate change, because of the availability of such records, but also because of the strong temperature dependence of the fruit crop life cycle (El Yaacoubi et al., 2014; Martínez-Lüscher et al., 2016). Although the vast majority of case studies have reported significant advances in flowering times over the years (Chmielewski et al., 2011; Chmielewski and Rotzer, 2001; Fitter and Fitter, 2002; Fu et al., 2015; Legave and Clauzel, 2006; Menzel et al., 2006; Parmesan, 2007; Parmesan and Yohe, 2003; Root et al., 2003; Wolfe et al., 2005), the literature includes a considerable number of records describing observations of flowering times that have remained unchanged or even experienced delays (Cook et al., 2012; Elloumi et al., 2013; Fitter and Fitter, 2002; Kozlov and Berlina, 2002; Legave et al., 2013; Menzel et al., 2006; Yu et al., 2010). Recent studies have indicated that the response of plant phenology to temperature is more complex than simply an advance due to warming (Andreini et al., 2014; Chuine et al., 2016; Cook et al., 2012; Guo et al., 2015; Pope et al., 2014).

Temperate deciduous trees enter a period of winter dormancy, during which they are leafless and their buds stay dormant awaiting suitable conditions to resume growth when temperatures rise. Apricots (Prunus armeniaca L.), like most temperate fruit crops, have an obligatory chilling requirement that must be fulfilled before trees can produce flowers (Campoy et al., 2011b; Luedeling, 2012). This means that they need a period of cool temperatures during the winter before normal budburst takes place (Campoy et al., 2011b; Campoy et al., 2013). The need to fulfil this chill requirement prevents these plants from flowering during short warm spells in winter, since flower 
development is prevented even when temperatures are favourable. The time when the chill requirement has been met marks the end of endo-dormancy. Subsequently, during the eco-dormant period, budburst can be induced by warm temperatures (Lang et al., 1987). It occurs after sufficient accumulation of heat above a base temperature (measured in Growing Degree Days or Growing Degree Hours), which is often cultivar/species dependent (Campoy et al., 2011a; Luedeling, 2012).

For modelling purposes, chill and heat requirements have been conceptualized in different ways. The most common concept is one of sequential fulfilment of chilling and heat requirements, in which there is a period, before fulfilment of the chilling requirement, when buds are insensitive to heat accumulation, followed by the warming phase, when additional chilling has no effect. After sufficient heat has then accumulated to fulfil the heat requirement, bud burst occurs (Darbyshire et al., 2013; Guedon and Legave, 2008; Luedeling et al., 2009). A rather different concept proposes that chilling and heat accumulation start at a similar time and budburst is possible after a combination of chilling and heat accumulation. This indicates a trade-off between chill and heat accumulation, with abundant heat being able to compensate for low chilling, and vice versa (Harrington and Gould, 2015; Harrington et al., 2010; Murray et al., 1989). This model assumes that plants with an obligatory chill requirement must first receive a minimum chilling dose (critical chilling units). Subsequently, high heat accumulation might induce bud burst. However, this heat requirement is reduced by exposure to additional chilling. Other modelling efforts for almonds have described this as an overlap between chilling and warming period, with a model assuming a budbreak-advancing effect of additional chilling until fulfilment of $75 \%$ of the heat requirement being best supported by field data (Pope et al., 2014). Experiments under controlled environment conditions also suggest that additional chilling during the early warming period may decrease the heat requirement (Couvillon and Erez, 1985). Since previous delineations between chilling and warming periods through PLS regression have also indicated an overlap between the phases, it seems plausible to differentiate between three temperature-responsive phases between the onset of bud dormancy and flowering: 1) only chilling accumulation has a flowering-advancing effect, 2) both chilling and 
heat accumulation are effective, and 3) only heat accumulation may promote bud development (Guo et al., 2014; Guo et al., 2015; Luedeling et al., 2013).

Although the effects of temperature on the fulfilment of chilling and heat requirements have been addressed by a large number of studies (e.g. Anzanello et al., 2014; Campoy et al., 2013; Carew et al., 2001; Mahmood et al., 2000), at the mechanistic level, the process responsible for chill accumulation is not fully understood (Campoy et al., 2011a).

In climates such as those encountered in the United Kingdom (145 Chill Portions [CP] accumulated on average from $1^{\text {st }}$ September to $31^{\text {st }}$ April), chilling is not typically assumed to be a limiting factor of flowering or crop yield of apricots (Guo et al., 2015; Viti et al., 2010). In addition, a calculation of chilling according to the Dynamic Model for future climate projections did not forecast major changes in the seasonal number of accumulated Chill Portions in the UK (Luedeling et al., 2011). However, assuming sequential completion of chilling and heat requirements, the current trend of climate warming may have an effect on the timing of the initiation of chilling, fulfilment of chilling, initiation of heat accumulation and completion of heat requirement, with all these factors having potential for major impacts on flowering dates (Luedeling et al., 2009). This leaves significant uncertainty about future trends in spring flowering of fruit species in the UK. In fact, studies conducted on wild species show a change in the order of flowering among species as temperatures increase (Roberts et al., 2015). It is also worth considering that, at present, apricots in the UK already flower relatively early, so that their timing often coincides with low activity of pollinators during anthesis, whilst buds, flowers and fruitlets face substantial risk of frost damage (Else and Atkinson, 2010). Further advances in apricot flowering dates may reduce their suitability for commercial plantings, whereas a delay in flowering may make them more suitable, particularly when associated with an increase in temperatures around flowering time (Cannell and Smith, 1986).

The aim of this study was to determine the influence of fluctuations in chill and heat accumulation on recorded flowering dates of apricots of the UK National Fruit Collections (NFC) in the SE England. 
We used Partial Least Squares (PLS) regression to determine the start and end of the effective chill and warming periods and to give an outlook of how variation in daily chill and heat accumulation rates affect the flowering date.

\section{Materials and Methods}

\subsection{Phenology and climate data}

This study used a 35-year discontinuous record of the flowering dates of 14 apricot varieties at the UK NFC at Brogdale Farm, Faversham, UK (51.30 $\mathrm{N}, 0.87^{\circ} \mathrm{E}, 12 \mathrm{~m}$ a.s.I.) observed between 1960 and 2014 (Table A1). Trees were generally monitored at least twice weekly (more frequently during particularly warm spells) and time of flowering was determined as the date when $10 \%$ of the flowers had fully opened. Dates were converted to Julian days (day of the year) for further analysis. There were no signs of any variety flowering earlier than the others (average range of 5.9 days; Fig. A.1). During several years, all varieties flowered on the same day or over a very short period (Fig. 1). The order in which different varieties flowered was not consistent throughout the record. For instance, the two varieties creating the largest flowering spread in the record (13 days in 1967 between Alfred and Sun-Glo), flowered only 2 days apart in the previous year. Another example is that Sun-Glo was the latest variety in 1981 but also the earliest three years later. Therefore, average flowering time for all varieties was used for the analyses. Among the 14 varieties, 'Alfred', 'Early Moorpark' and 'Farmingdale' were represented in most of the 35 years when flowering was recorded (Table A1), allowing meaningful trend analysis for these varieties.

Daily minimum and maximum temperatures were collected from a meteorological station located near the apricot orchard. A gap in the meteorological data, from March $1^{\text {st }}$ of 1990 to April $30^{\text {th }}$ of 1998, was filled with data from the nearest weather station available (East Malling, $51.29^{\circ} \mathrm{N} ; 0.45^{\circ} \mathrm{E}$, $78 \mathrm{~m}$ a.s.l., ca. $30 \mathrm{~km}$ away). These data were corrected for the 0.19 and $-0.19^{\circ} \mathrm{C}$ difference in mean daily minimum and maximum temperatures determined by analysing differences between the records for overlapping periods. Minor gaps in the meteorological data were filled by linear 
interpolation. These gaps were 14 recordings of daily maximum temperature and 29 of daily minimum temperature scattered throughout the whole time series.

\subsection{Chilling and heat accumulation models}

Most common chill and heat models require hourly temperature data as inputs. These were constructed using recorded (and gap-filled) daily minimum and maximum temperature records and following the recommendations of Linvill (1990) that the daily temperature curve can be composed of a sine curve for daytime warming and a logarithmic decay function for night-time cooling. Since these equations require daily data on sunrise, sunset and day length as inputs, these were modelled based on geographic latitude (Almorox et al., 2005; Spencer, 1971).

Daily chill accumulation was calculated according to the Dynamic Model (Erez et al., 1990; Fishman et al., 1987b), as it has consistently shown a better performance than other chill models in a wide range of circumstances (Campoy et al., 2011a; Darbyshire et al., 2011; Erez et al., 1990; Guo et al., 2013; Luedeling et al., 2013; Luedeling et al., 2009). Daily heat accumulation was calculated according to the Growing Degree Hours (GDH) Model (Anderson et al., 1986), a curvilinear model using a base temperature of $4^{\circ} \mathrm{C}$ and an optimum temperature of $26^{\circ} \mathrm{C}$. The equations used for these chill and heat accumulation models are given in Luedeling and Brown (2011) and Luedeling et al. (2009), respectively. To facilitate the visual interpretation of the results, daily chill and heat values were subjected to an 11-day running mean procedure (Luedeling and Gassner, 2012; Luedeling et al., 2013). We illustrated variance of chill or heat accumulation over the periods of responsiveness using the standard deviation.

\subsection{Partial Least Squares regression}

Daily chill and heat accumulation were related to flowering dates for each year from $1^{\text {st }}$ June to $25^{\text {th }}$ April (latest flowering date recorded), creating 35 datasets consisting of 328 records of daily chill and heat accumulation (ignoring $25^{\text {th }}$ April in leap years) and one flowering date each. PLS regression was 
then used to find correlations between daily chill and heat accumulation rates (656 independent variables -328 daily chill and 328 daily heat values) and flowering date ( 1 dependent variable). The Variable Importance in the Projection (VIP) statistic of PLS regression was used to highlight the most important among the large number of predictor variables. In contrast to other regression methods, PLS regression can effectively analyse effects of a large number of highly autocorrelated variables, even when they greatly outnumber the observations for the independent variables. For PLS regression, two latent factors were constructed from all the independent variables and used to perform a regression with the dependent variable, in line with the methods of Wold et al. (2001). We used the PLS implementation in the chillR package for $R$ programming language ( $R$ version 3.2.0) (Luedeling, 2013). PLS regression gives two major outputs for each predictor variable: the VIP and a model coefficient. The VIP indicates how important variation in the value of a particular variable is for explaining variation in the dependent variable. As in previous studies, 0.8 was assumed to signify importance of a variable (Luedeling et al., 2013; Wold et al., 2001). For those independent variables with a significant VIP score, positive or negative PLS model coefficients indicate that a positive or negative deviation in the independent variable is correlated to an increase or decrease in the dependent variable, respectively. For our purposes, a negative coefficient on daily chill or heat accumulation indicates that high heat or chill accumulation on that particular day of the year is correlated to early spring flowering. Positive coefficients indicate correlation of high heat or chill accumulation with late flowering dates.

\subsection{Interpretation of PLS output}

PLS regression highlights phases during which variation in independent variables (daily accumulation of chilling and heat) is correlated with variation in flowering date. Therefore, PLS regression analysis of a sufficiently long record of variable winter weather and the resulting flowering dates should allow delineation of relevant temperature response phases (Luedeling and Gassner, 2012; Luedeling 
weather conditions on these days had no chilling or heat accumulation effect. It may simply mean that variation in weather conditions was not correlated with variation in flowering dates, which may also occur when, for example, temperatures varied only within a range that was optimal for chilling.

\subsection{Response of fruit tree flowering to conditions during the chilling and warming periods}

197

198

Once the chilling and warming periods were delineated, we determined heat accumulation during the warming phase (in $\mathrm{GDH}$ ), chill accumulation during the chilling phase (in $\mathrm{CP}$ ) and mean temperature during the chilling and warming periods. Other relevant parameters calculated were the day of the year when the first $5 \mathrm{CP}$ (starting from $1^{\text {st }}$ of July), the average chilling accumulation that enabled heat accumulation (first $62.7 \mathrm{CP}$ starting from $1^{\text {st }}$ of July) and the first $1000 \mathrm{GDH}$ of the year (starting from $1^{\text {st }}$ of January) had accumulated. The Kendall rank correlation coefficient ( $\tau$, tau) was calculated for time series evaluation, and linear regression lines were plotted for chilling and warming period mean temperatures, chill and heat accumulation, completion date of the first 1000 $\mathrm{GDH}$, completion date of the first $5 \mathrm{CP}$ and completion date of the average chill accumulation that enabled heat accumulation. Kendall's test is a non-parametric test where values are substituted by ranks, this means that no distribution or linear relationship is assumed. For this reasons Kendall's test is widely used for detecting trends in climatologic time series (Wilks, 2011). We used Pearson's correlation test for other data different from time series.

Through interpolation, we created a response surface illustrating the dependency of apricot flowering on chill and heat accumulation during the chilling and warming phases. For the interpolation, we used the Kriging technique, which is a Gaussian regression method commonly used in spatial statistics to estimate values at locations where no data are available (Oliver and Webster, 1990). This illustration facilitated the interpretation of responses of flowering dates to multiple climatic drivers. In this case, the plot illustrated the direction and magnitude of the effects of chilling and heat accumulation on flowering dates (Guo et al., 2015). Guo et al. (2015) showed that as temperatures increase, temperatures during the chilling period may gain in relative influence on 
bloom dates, compared to temperatures during the heat phase. However, within any single site, the relative importance of temperatures during these two phases appears to be relatively constant (Guo et al. 2015), unless temperatures increase very strongly, or the study site is already marginal for the species in terms of chilling. The kriging surface can be approximated by a bivariate linear model: $y=$ $a T_{c}+b T_{h}+c$; where $T_{c}$ is temperature during the chilling period, $a$ is the sensitivity of flowering date to chilling period temperature, $T_{h}$ is temperature during the warming period, and $b$ is the sensitivity of flowering date to warming period temperature. This method is often used with linear univariate models to estimate the sensitivity of phenology to changes in spring temperature (Fu et al., 2015).

\section{Results}

\subsection{Evolution of apricot flowering over time}

The average flowering date of apricots of the UK NFC showed a large degree of variability from year to year, being as early as $10^{\text {th }}$ March in 1961 and 1989 and as late as $25^{\text {th }}$ April in 1986 (Fig. 1), with 46 days between earliest and latest flowering dates. Flowering time showed a slight trend towards earlier dates over the recording period (average advance by 0.238 days per year $\left[\mathrm{d} \mathrm{yr}^{-1}\right]$ ), but this was not statistically significant $(\tau=-0.13 ; p=0.293)$. The same results were observed for the three most frequently observed varieties; 'Alfred' $\left(-0.092\left[\mathrm{~d} \mathrm{yr}{ }^{-1}\right] ; \tau=-0.07 ; \mathrm{p}=0.621\right)$, 'Early Moorpark' $(-0.29$ $\left.\left[d \mathrm{yr}^{-1}\right] ; \tau=-0.20 ; p=0.149\right)$ and 'Farmingdale' $\left(-0.141\left[\mathrm{~d} \mathrm{yr}^{-1}\right] ; \tau=-0.09 ; \mathrm{p}=0.568\right)$.

\subsection{Relevant periods for chill and heat accumulation}

Results from the PLS regression procedure indicated a period between $27^{\text {th }}$ September and $26^{\text {th }}$ February, which was characterized by high VIP scores $(>0.8)$ and negative model coefficients for the chill accumulation rate (Fig. 2). This phase was interrupted by a period between October and December, during which the correlation between variation in chill accumulation and flowering dates was not very pronounced. However, the daily chill accumulation rate during this time span was consistently high and varied relatively little, so that it seemed reasonable to us to interpret the 
entire period between $27^{\text {th }}$ September and $26^{\text {th }}$ February as the chilling period. There were two additional periods of significant VIP scores for chill accumulation, where coefficients were alternating between positive and negative: 1 ) from $1^{\text {st }}$ June to $4^{\text {th }}$ July, and 2) from $10^{\text {th }}$ March to $9^{\text {th }}$ April. The fact that coefficients were not consistently positive or negative suggests that this pattern may not reflect the physiological processes commonly associated with dormancy progression. However, PLS analyses of mean temperatures (rather than chilling and forcing rates; Fig A. 2) also shows significant VIP scores and negative coefficients for both periods, which may indicate that apricot buds are truly responsive to temperatures during these periods.

The delineation of the warming period was clearer, with an almost uninterrupted period from $31^{\text {st }}$ December to $12^{\text {th }}$ April with negative model coefficients for daily heat accumulation rate, coupled with high VIP values. Chill accumulation over the chilling period was $103.7 \pm 7.2 \mathrm{CP}$, including $41.7 \pm$ 4.3 CP in the period when chill and heat accumulation overlapped. This suggests that the difference, $62.7 \pm 5.6 \mathrm{CP}$, accumulated from $27^{\text {th }}$ September to $31^{\text {st }}$ December, is the amount of chilling that these apricot trees received before starting to accumulate thermal time. The GDH accumulation during the overlapping period (from $1^{\text {st }}$ January to $26^{\text {th }}$ February) was $1269 \pm 681$, and this was followed by another $2511 \pm 1062 \mathrm{GDH}$ between $26^{\text {th }}$ February and $12^{\text {th }}$ April, resulting in a total accumulation of $3744 \pm 1538 \mathrm{GDH}$ accumulation in total (from $1^{\text {st }}$ January to $12^{\text {th }}$ April).

PLS results also indicated that the effects of heat accumulation depended strongly on when heat accumulation occurred (Fig. 2). Daily GDH showed also two periods of positive coefficients, when warm periods were correlated with late, rather than early, flowering dates: 1) from $4^{\text {th }}$ to $16^{\text {th }}$ of October, and 2) from $9^{\text {th }}$ to $31^{\text {st }}$ of December. During the first period, daily chilling accumulation was also correlated with flowering delays. This phase approximately coincided with the only period, for which high mean temperatures where associated with late flowering (Fig. A.2). In fact, the date of 
completion of the first $5 \mathrm{CP}$ was correlated with the heat accumulation required up to flowering (Fig. A.3).

\subsection{Relative importance of warming effects during the chilling and heat accumulation} phases

Plotting flowering dates of apricot as a function of temperature during the chilling and warming periods predicted by PLS showed effects of both factors (Fig. $3 A, R^{2}=0.74$ ). Cooler temperatures during the chilling period and warmer temperatures during the warming period appeared to induce earlier flowering. Since mean temperatures during the chilling and warming periods were positively correlated $(r=0.79 ; p<0.001$; data not shown), our dataset did not contain years with very warm chilling and cool heat accumulation phases, or vice versa (Fig. 3A). Had the data included such records, the bloom-advancing effect of cool temperatures would likely have featured more prominently in our results. Given that contour lines are nearly straight and parallel, the kriging surface could be approximated by a bivariate linear model $\left(R^{2}=0.99\right): y=4.82 * T_{c}-9.85 * T_{w}+109.5$; where $y$ is the flowering date (Julian Day), $T_{c}$ is the mean temperature during the chilling period, $T_{w}$ is the mean temperature during the warming period, 4.82 days ${ }^{\circ} \mathrm{C}^{-1}$ is the sensitivity to temperature during the warming period, -9.85 days ${ }^{\circ} \mathrm{C}^{-1}$ is the sensitivity to temperature during the warming period and 109.5 days is the model intercept (see methods for details). The angle of the contour lines, closer to parallel with the $\mathrm{X}$ axis than the $\mathrm{Y}$ axis and the greater sensitivity to temperatures during the warming period than the chilling period (-9.85 vs 4.82 days $\left.{ }^{\circ} \mathrm{C}^{-1}\right)$ suggests that apricot flowering dates were influenced more strongly by temperature during the warming period than by temperature during the chilling phase. The combined effect of chill and heat accumulation described apricot flowering dates well (Fig. $\left.3 B, R^{2}=0.67\right)$. The plot indicated a greater influence of variation in heat accumulation on flowering dates, but also showed a pronounced effect of chill accumulation rates, resulting in diagonal contour lines.

\subsection{Evolution of temperature-related variables over time}


Temperature during both chilling and warming periods increased significantly over time $(\tau=0.35$; $p<0.001$; Fig. $4 A$ and $\tau=0.36 ; p<0.001 ;$ Fig. 4D). However, throughout the temperature record, mean temperature showed a slightly greater increase during the warming period $\left(0.039{ }^{\circ} \mathrm{C} \mathrm{yr}^{-1}\right)$ than during the chilling period $\left(0.026{ }^{\circ} \mathrm{C} \mathrm{yr}^{-1}\right)$. In contrast, heat accumulation showed a positive and significant trend over the period recorded $(\tau=0.40 ; p<0.001$; Fig $4 B)$, but not chill accumulation $(\tau=0.02$; $p=0.794 ;$ Fig. 4E). Despite the lack of significant trend in chilling accumulation over time, the time to accumulate the first $5 \mathrm{CP}$ of the season was significantly delayed over the years $\left(0.28 \mathrm{~d} \mathrm{yr}^{-1} ; \tau=0.26\right.$; $p=0.005$; Fig. $4 \mathrm{~F}$ ), leading to a delay in the time to complete the average chilling accumulation that enabled heat accumulation ( first $62.7 \mathrm{CP} ; 0.21 \mathrm{~d} \mathrm{yr}^{-1} ; \tau=0.25 ; \mathrm{p}=0.006$; Fig. 4G). The time to

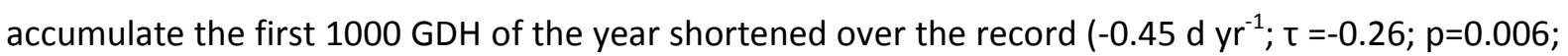
Fig. 4C). Mean temperatures around flowering showed a significant positive correlation with time $\left(0.022^{\circ} \mathrm{C}^{-1} ; \tau=0.28 ; p=0.02 ;\right.$ Fig. 5).

\section{Discussion and conclusions}

\subsection{Identification of chilling and warming periods by PLS regression}

Chilling and warming periods are often designated arbitrarily, based on intuition, or counting from the first day that chilling starts to accumulate (Darbyshire et al., 2011; Harrington and Gould, 2015; Harrington et al., 2010; Luedeling and Brown, 2011). In previous studies, PLS regression has been able to identify clearly the days of the year when accumulation of chilling or heat had an impact on spring phenology, so that chilling and warming periods could be defined (Guo et al., 2014; Guo et al., 2015; Luedeling and Gassner, 2012; Luedeling et al., 2013). This approach can also identify the chilling period for crops and places where the chilling requirement is easily satisfied (Guo et al., 2014) and variation in chilling accumulation has a small influence on flowering dates. In the present study, effective chilling and warming periods for apricots in the UK National Fruit Collection occurred from $27^{\text {th }}$ September to $26^{\text {th }}$ February and from $31^{\text {st }}$ December to $12^{\text {th }}$ April, respectively. Thus, the identified chilling and warming periods had a significant overlap of 58 days. This is in agreement with 
studies on apricot and peach, which showed 1) an initial phase when heat accumulation cannot induce budburst, 2) a period when sufficient chill has accumulated to induce budburst by application of warm conditions, with the amount of required heat decreasing with additional chill accumulation and 3) a phase when additional chill has no effect and only heat is required for budburst (Campoy et al., 2011b; Campoy et al., 2013; Okie and Blackburn, 2011).

Guo et al. (2015) identified chilling and warming periods of apricots by PLS regression for several locations in China, among which results from our study were most similar to the analysis for Beijing, which was reported to have a chilling period from $17^{\text {th }}$ September to $26^{\text {th }}$ February. Considering the differences in temperature between locations at the start and end of the chilling period, this is a PLS regression indicated similar chilling but also warming periods (from $9^{\text {th }}$ January to $10^{\text {th }}$ April in Beijing). Both locations were also similar in terms of the relative contributions of temperatures during the chilling and warming periods to variation in flowering dates (Fig. $3 \mathrm{~A})$. Therefore, in spite of big differences between the climates of Beijing and SE England, our results support the hypothesis reverse the advances in spring events that have been observed in recent decades.

In a study comparing the flowering dates of late varieties of apricot in Italy (Fideghelli et al., 1978), 'Alfred' and 'Farmingdale' came out among the latest of the 146 varieties recorded, with the same 
Moorpark', the third variety constituting the core of the data used for the analyses, flowered just 5 days earlier than the other two. It must be noted that the late flowering of the varieties of the UK NFC led to the identification of the given chilling and warming periods and the use of varieties with lower chill requirements would have led to different periods (Guo et al., 2015).

The chilling accumulation before the period of heat accumulation at the study site $\left(27^{\text {th }}\right.$ September to $31^{\text {st }}$ December) and the subsequent heat accumulation was $62.7 \pm 5.6 \mathrm{CP}$ and $3744 \pm 1538 \mathrm{GDH}$, respectively. This is similar to the requirements reported by Ruiz et al. (2007) for 'Bergeron' in a very different climate (SW Spain) of $64.8 \mathrm{CP}$ for breaking dormancy and $4101 \mathrm{GDH}$ from breaking dormancy to flowering. Similar accumulations were reported by Campoy et al. (2012) for 'Bergeron', together with a relatively high interannual variation in the estimation of both chilling and heat accumulations required to flower. The overlap between the chilling and warming periods found in this study and Guo et al. (2015) may offer the key to understanding the variability in the estimation of this important horticultural trait. In cold places, some years may not allow heat accumulation soon after buds have received enough chilling to break endo-dormancy. In this case, additional chilling may reduce the amount of heat required for flowering. In warmer places, however, in years with slightly lower chilling accumulation than the optimal required, additional heat can still trigger flowering (Harrington et al., 2010). This trade-off could be responsible for the interannual variability often reported in chill and heat requirement estimations. Assuming an overlap between chilling and warming periods has been shown to improve model fits (Darbyshire et al., 2016; Pope et al., 2014). or interactions between chill and heat cannot be captured.

4.2 Impacts of chilling and heat accumulation conditions on flowering dates period (Fig. 3). Similar findings have previously been reported for apricots in China, France, Italy and 
Spain (Andreini et al., 2014; Guo et al., 2015), chestnut and jujube in China (Guo et al., 2014), and apples and olives in France (El Yaacoubi et al., 2014). El Yaacoubi et al. (2014) analysed the spring phenology of different tree crops in different locations and noted that late flowering crops were more prone to earlier flowering in response to increasing temperature. The abundance of records showing a trend towards earliness may also be linked to the growers choosing species and cultivars with appropriate chilling requirements for their growing region. So far, it is only in very warm production regions, where available chill is barely sufficient for growing certain temperate species, that significant delays in spring flowering in response to warming have been observed (Elloumi et al., 2013; Luedeling et al., 2013).

PLS regression showed two periods when flowering was delayed by heat accumulation: 1) at the beginning of the chilling period, 2) and before the start of the warming period. For the first period, this effect may be related to the delaying impact of high summer/autumn temperature on growth cessation, which has been reported to potentially lead to delayed bud burst in the following year (Heide, 2003; Heide and Prestrud, 2005). In addition, the timing of the onset of chill accumulation (first $5 \mathrm{CP}$ completion) appeared to increase the amount of heat required for flowering (Fig. A.3), suggesting that the timing of the first chill accumulation is important for counteracting the flowering-advancing effect of temperatures during the warming period. In the second case (i.e. the period of significant positive correlation for heat accumulation before the warming period, in the middle of the chilling period), controlled environment studies show that when heat is received too early, before critical chilling completion, it may not advance or even delay flowering (Anzanello et al., 2014). In the present study, the low heat accumulation during this period (i.e. right before the warming period) suggests that even though VIP scores were high, heat accumulation during this period probably had little effect. Chill accumulation also presented periods with high VIP that were outside the delineated chilling period (e.g. from $1^{\text {st }}$ June to $4^{\text {th }}$ July). Given that buds for the next year are not yet present at that time, this is probably not a biologically meaningful effect. 
392

393

394

395

In spite of global warming, in the UK, chill accumulation calculated using the Dynamic Model has decreased only slightly in recent decades, and no major decreases over the $21^{\text {st }}$ century have been projected for future scenarios based on the CSIRO, HADCM3 and MIROC climate models (Luedeling et al., 2011). Our results show a significant increasing trend in mean temperatures during the chilling period of apricots, but no significant decrease in chill accumulation (Fig. 4D and E). It is worth noting that the Dynamic Model considers that, as long as temperatures during the day are not too high, 4 hours at low temperature (i.e. $6^{\circ} \mathrm{C}$ ) and 20 hours at moderate temperature (i.e. $14^{\circ} \mathrm{C}$ ) per day are $63 \%$ as effective as a regime with 24 hours at cold temperature (Fishman et al., 1987a). In consequence, the increase in mean temperature during the chilling period over the record did not correspond to a decrease in chill accumulation according to this model. In addition, for coldtemperate climates, increasing temperatures frequently shift temperatures to levels to which most chill models would assign higher-rather than lower-chilling effectiveness, resulting in no change or even increase in chilling (Luedeling et al., 2011). Even though according to the Dynamic Model, overall chill during the chilling period did not decrease $(\tau=0.02, p=0.79)$, the time to accumulate the first $5 \mathrm{CP}$ and $62.7 \mathrm{CP}$ (average chill accumulation that enabled heat accumulation) increased over the years. This may be an indication of a gradual shift of the chilling period. This delayed start of chill accumulation is unlikely to induce a reduction of chill accumulation per se in the short term, as the date identified as the end of the chilling period $\left(26^{\text {th }}\right.$ February) is still succeeded by many days with high daily chill accumulation. However, this delay in chilling may delay chill requirement fulfilment and subsequent events, such as the start of the warming period, budburst and flowering. Simultaneously, heat accumulation increased and the time to accumulate the first 1000 GDH decreased over the years. If the start of the chilling and warming period continues to be delayed, while the accumulation of heat occurs earlier in the year, the net effect on spring event timing is difficult to predict. Possibilities then include continued advances (if additional heat accumulation is the dominant driver), unchanged flowering times (if effects cancel each other out) or even delays (if 
delayed chill accumulation becomes dominant; Guo et al., 2015). In addition to the influence of conditions during the chilling and warming periods, our results highlight the relevance of the timing of multiple events for explaining variation in spring phenology.

As for the future suitability of this crop, temperatures before and after flowering are important for successful production, because of the need to synchronize bloom with pollinator activity (Else and Atkinson, 2010). Cannell and Smith (1986) found that future warming could increase the incidence of frost damage to the flowers of trees in Britain, but it could also cause the opposite, depending on the extent to which trees' chilling requirements are currently met. In this work we showed that warming likely delays chill accumulation, partially compensating for advances in response to warmer springs, resulting in warmer temperatures in the dates before and after flowering. If this trend is maintained, further warming may therefore reduce the frost risk for apricots in SE England rather than the opposite.

\subsection{Conclusions}

In recent years, flowering in apricot has been experiencing an advancing effect related to increased temperature during the effective warming period. However, a delay in the onset of chill accumulation and completion of chill requirement necessary to start heat accumulation appear to moderate the effect of increasing heat during the warming period. Although the future trend in flowering dates of apricots in the UK is unclear, as temperature continues to increase during both chilling and warming periods, the trend to earliness in flowering induced by warming temperatures may continue being balanced by the apparent bloom-delaying effect of temperature during the chilling phase. Increases in temperatures around flowering time over the years, however, suggest that the southern UK many potentially become a more suitable region for apricots in the future due to the associated reduced risk of frost damage. 
This research was supported by the Land Settlement Association, the University of Reading Research

Endowment Trust, East Malling Trust and research program on 'Water, Land and Ecosystems' of the

Consultative Group on International Agricultural Research (CGIAR). We would like to thank the previous curators of the UK National Fruit Collection, who have also collected flowering data over many years, especially Mary Pennell. The National Fruit collections are supported by the UK

Department of Environment, Food and Rural Affairs (Defra). We thank the two anonymous

References

Almorox, J., Hontoria, C. and Benito, M., 2005. Statistical validation of daylength definitions for estimation of global solar radiation in Toledo, Spain. Energy Conversion and Management, 46(9-10): 1465-1471. doi: 10.1016/j.enconman.2004.07.007

Anderson, J.L., Richardson, E.A. and Kesner, C.D., 1986. Validation of chill unit and flower bud phenology models for 'Montmercy' sour cherry. Acta Horticulturae: 71-78. doi: 10.17660/ActaHortic.1986.184.7

Andreini, L., de Cortazar-Atauri, I.G., Chuine, I., Viti, R., Bartolini, S., Ruiz, D., Antonio Campoy, J., Legave, J.M., Audergon, J.-M. and Bertuzzi, P., 2014. Understanding dormancy release in apricot flower buds (Prunus armeniaca L.) using several process-based phenological models. Agricultural and Forest Meteorology, 184: 210-219. doi: 10.1016/j.agrformet.2013.10.005

Anzanello, R., Fialho, F.B., Santos, H.P.d., Bergamaschi, H. and Marodin, G.A.B., 2014. Bud dormancy in apple trees after thermal fluctuations. Pesquisa Agropecuaria Brasileira, 49: 457-464.

Campoy, J.A., Ruiz, D., Allderman, L., Cook, N. and Egea, J., 2012. The fulfilment of chilling requirements and the adaptation of apricot (Prunus armeniaca L.) in warm winter climates: An approach in Murcia (Spain) and the Western Cape (South Africa). European Journal of Agronomy, 37(1): 43-55. doi: 10.1016/j.eja.2011.10.004 
Campoy, J.A., Ruiz, D. and Egea, J., 2011a. Dormancy in temperate fruit trees in a global warming context: A review. Scientia Horticulturae, 130(2): 357-372. doi: 10.1016/j.scienta.2011.07.011

Campoy, J.A., Ruiz, D. and Egea, J., 2011b. Seasonal progression of bud dormancy in apricot (Prunus armeniaca L.) in a Mediterranean climate: A single-node cutting approach. Plant Biosystems - An International Journal Dealing with all Aspects of Plant Biology, 145(3): 596-605. doi: $10.1080 / 11263504.2011 .559361$

Campoy, J.A., Ruiz, D., Nortes, M.D. and Egea, J., 2013. Temperature efficiency for dormancy release in apricot varies when applied at different amounts of chill accumulation. Plant Biology, 15 Suppl 1: 28-35. doi: 10.1111/j.1438-8677.2012.00636.x

Cannell, M.G.R. and Smith, R.I., 1986. Climatic warming, spring budburst and frost damage on trees. Journal of Applied Ecology, 23(1): 177-191. doi: 10.2307/2403090

Carew, J.G., Mahmood, K., Darby, J., Hadley, P. and Battey, N.H., 2001. The effects of low temperatures on the vegetative growth and flowering of the primocane fruiting raspberry 'Autumn Bliss'. Journal of Horticultural Science \& Biotechnology, 76(3): 264-270. doi: $10.1080 / 14620316.2001 .11511361$

Chmielewski, F.M., Blumel, K., Henniges, Y., Blanke, M., Weber, R.W.S. and Zoth, M., 2011. Phenological models for the beginning of apple blossom in Germany. Meteorologische Zeitschrift, 20(5): 487-496. doi: 10.1127/0941-2948/2011/0258

Chmielewski, F.M. and Rotzer, T., 2001. Response of tree phenology to climate change across Europe. Agricultural and Forest Meteorology, 108(2): 101-112. doi: 10.1016/S01681923(01)00233-7

Chuine, I., Bonhomme, M., Legave, J.-M., García de Cortázar-Atauri, I., Charrier, G., Lacointe, A. and Améglio, T., 2016. Can phenological models predict tree phenology accurately in the future? The unrevealed hurdle of endodormancy break. Global Change Biology, 22(10): 3444-3460. doi: $10.1111 / g c b .13383$ 
Cook, B.I., Wolkovich, E.M. and Parmesan, C., 2012. Divergent responses to spring and winter warming drive community level flowering trends. Proceedings of the National Academy of Sciences of the United States of America, 109(23): 9000-9005. doi: 10.1073/pnas.1118364109

Couvillon, G.A. and Erez, A., 1985. Effect of level and duration of high temperatures on rest in the peach. Journal of the American Society for Horticultural Science, 110(4): 579-581.

Darbyshire, R., Pope, K. and Goodwin, I., 2016. An evaluation of the chill overlap model to predict flowering time in apple tree. Scientia Horticulturae, 198: 142-149. doi: 10.1016/j.scienta.2015.11.032

Darbyshire, R., Webb, L., Goodwin, I. and Barlow, E.W., 2013. Evaluation of recent trends in Australian pome fruit spring phenology. International Journal of Biometeorology, 57(3): 40921. doi: $10.1007 / \mathrm{s} 00484-012-0567-1$

Darbyshire, R., Webb, L., Goodwin, I. and Barlow, S., 2011. Winter chilling trends for deciduous fruit trees in Australia. Agricultural and Forest Meteorology, 151(8): 1074-1085. doi: 10.1016/j.agrformet.2011.03.010

El Yaacoubi, A., Malagi, G., Oukabli, A., Hafidi, M. and Legave, J.-M., 2014. Global warming impact on floral phenology of fruit trees species in Mediterranean region. Scientia Horticulturae, 180: 243-253. doi: 10.1016/j.scienta.2014.10.041

Elloumi, O., Ghrab, M., Kessentini, H. and Ben Mimoun, M., 2013. Chilling accumulation effects on performance of pistachio trees cv. Mateur in dry and warm area climate. Scientia Horticulturae, 159: 80-87. doi: 10.1016/j.scienta.2013.05.004

Else, M. and Atkinson, C., 2010. Climate change impacts on UK top and soft fruit production. Outlook on Agriculture, 39(4): 257-262. doi: 10.5367/oa.2010.0014

Erez, A., Fishman, S., Linsley-Noakes, G.C. and Allan, P., 1990. The dynamic model for rest completion in peach buds. Acta Horticulturae(276): 165-174. doi: 10.17660/ActaHortic.1990.276.18 
Fideghelli, C., Della Strada, G., Monastra, F., Quarta, R. and Crisafulli, A., 1978. Costituzione di cultivar di albicocco a fioritura tardiva. Rivista di ortoflorofrutticoltura italiana, 62(6): 603614.

Fishman, S., Erez, A. and Couvillon, G.A., 1987a. The temperature dependence of dormancy breaking in plants: Computer simulation of processes studied under controlled temperatures. Journal of Theoretical Biology, 126(3): 309-321. doi: 10.1016/S0022-5193(87)80237-0

Fishman, S., Erez, A. and Couvillon, G.A., 1987b. The temperature dependence of dormancy breaking in plants: Mathematical analysis of a two-step model involving a cooperative transition. Journal of Theoretical Biology, 124(4): 473-483. doi: 10.1016/S0022-5193(87)80221-7

Fitchett, J.M., Grab, S.W. and Thompson, D.I., 2015. Plant phenology and climate change: Progress in methodological approaches and application. Progress in Physical Geography. doi: $10.1177 / 0309133315578940$

Fitter, A.H. and Fitter, R.S.R., 2002. Rapid changes in flowering time in British plants. Science, 296(5573): 1689-1691. doi: 10.1126/science.1071617

Fu, Y.S.H., Zhao, H.F., Piao, S.L., Peaucelle, M., Peng, S.S., Zhou, G.Y., Ciais, P., Huang, M.T., Menzel, A., Uelas, J.P., Song, Y., Vitasse, Y., Zeng, Z.Z. and Janssens, I.A., 2015. Declining global warming effects on the phenology of spring leaf unfolding. Nature, 526(7571): 104-+. doi: $10.1038 /$ nature15402

Guedon, Y. and Legave, J.M., 2008. Analyzing the time-course variation of apple and pear tree dates of flowering stages in the global warming context. Ecological Modelling, 219(1-2): 189-199. doi: 10.1016/j.ecolmodel.2008.08.010

Guo, L., Dai, J., Ranjitkar, S., Xu, J. and Luedeling, E., 2013. Response of chestnut phenology in China to climate variation and change. Agricultural and Forest Meteorology, 180: 164-172. doi: 10.1016/j.agrformet.2013.06.004 
541 Guo, L., Dai, J., Ranjitkar, S., Yu, H., Xu, J. and Luedeling, E., 2014. Chilling and heat requirements for flowering in temperate fruit trees. International Journal of Biometeorology, 58(6): 1195-206. doi: 10.1007/s00484-013-0714-3

Guo, L., Dai, J., Wang, M., Xu, J. and Luedeling, E., 2015. Responses of spring phenology in temperate zone trees to climate warming: A case study of apricot flowering in China. Agricultural and Forest Meteorology, 201: 1-7. doi: 10.1016/j.agrformet.2014.10.016

Harrington, C.A. and Gould, P.J., 2015. Tradeoffs between chilling and forcing in satisfying dormancy requirements for Pacific Northwest tree species. Frontiers in Plant Science, 6: 120. doi:

Harrington, C.A., Gould, P.J. and St.Clair, J.B., 2010. Modeling the effects of winter environment on dormancy release of Douglas-fir. Forest Ecology and Management, 259(4): 798-808. doi:

Heide, O.M., 2003. High autumn temperature delays spring bud burst in boreal trees, counterbalancing the effect of climatic warming. Tree Physiology, 23(13): 931-6. doi:

Heide, O.M. and Prestrud, A.K., 2005. Low temperature, but not photoperiod, controls growth cessation and dormancy induction and release in apple and pear. Tree Physiology, 25(1): 109-14. doi: 10.1093/treephys/25.1.109

Kozlov, M.V. and Berlina, N.G., 2002. Decline in Length of the Summer Season on the Kola Peninsula, Russia. Climatic Change, 54(4): 387-398. doi: 10.1023/a:1016175101383

Lang, G.A., Early, J.D., Martin, G.C. and Darnell, R.L., 1987. Endo-, para-, and ecodormancy: physiological terminology and classification for dormancy research. Horticultural Science, 22: 371-377.

Legave, J.M., Blanke, M., Christen, D., Giovannini, D., Mathieu, V. and Oger, R., 2013. A comprehensive overview of the spatial and temporal variability of apple bud dormancy 
release and blooming phenology in Western Europe. International Journal of Biometeorology, 57(2): 317-31. doi: 10.1007/s00484-012-0551-9

568

569

570

571

572

573

Legave, J.M. and Clauzel, G., 2006. Long-term evolution of flowering time in apricot cultivars grown in Southern France: Which future impacts of global warming? Proceedings of the $\mathrm{XIII}^{\text {th }}$ International Symposium on Apricot Breeding and Culture, (717): 47-50.

Linvill, D.E., 1990. Calculating chilling hours and chill units from daily maximum and minimum temperature observations. Hortscience, 25(1): 14-16.

Luedeling, E., 2012. Climate change impacts on winter chill for temperate fruit and nut production: A review. Scientia Horticulturae, 144: 218-229. doi: 10.1016/j.scienta.2012.07.011

Luedeling, E., 2013. chillR: Statistical methods for phenology analysis in temperate fruit trees. R Package Version 0.54. http://cran.r-project.org/web/packages/chillR.

Luedeling, E. and Brown, P.H., 2011. A global analysis of the comparability of winter chill models for fruit and nut trees. International Journal of Biometeorology, 55(3): 411-21. doi: $10.1007 / \mathrm{s} 00484-010-0352-y$

Luedeling, E. and Gassner, A., 2012. Partial Least Squares Regression for analyzing walnut phenology in California. Agricultural and Forest Meteorology, 158-159: 43-52. doi: 10.1016/j.agrformet.2011.10.020

Luedeling, E., Girvetz, E.H., Semenov, M.A. and Brown, P.H., 2011. Climate change affects winter chill for temperate fruit and nut trees. Plos One, 6(5): e20155. doi: 10.1371/journal.pone.0020155

Luedeling, E., Kunz, A. and Blanke, M.M., 2013. Identification of chilling and heat requirements of cherry trees-a statistical approach. International Journal of Biometeorology, 57(5): 679-89. doi: 10.1007/s00484-012-0594-y

Luedeling, E., Zhang, M., McGranahan, G. and Leslie, C., 2009. Validation of winter chill models using historic records of walnut phenology. Agricultural and Forest Meteorology, 149(11): 18541864. doi: 10.1016/j.agrformet.2009.06.013 
Mahmood, K., Carew, J.G., Hadley, P. and Battey, N.H., 2000. Chill unit models for the sweet cherry cvs Stella, Sunburst and Summit. Journal of Horticultural Science \& Biotechnology, 75(5): 602-606. doi: 10.1080/14620316.2000.11511293

Martínez-Lüscher, J., Kizildeniz, T., Vučetić, V., Dai, Z., Luedeling, E., van Leeuwen, C., Gomès, E., Pascual, I., Irigoyen, J.J., Morales, F. and Delrot, S., 2016. Sensitivity of Grapevine Phenology to Water Availability, Temperature and $\mathrm{CO}_{2}$ Concentration. Frontiers in Environmental Science, 4(48). doi: 10.3389/fenvs.2016.00048

Menzel, A., Estrella, N. and Schleip, C., 2008. Impacts of climate variability, trends and NAO on $20^{\text {th }}$ century European plant phenology. In: S. Brönnimann et al. (Editors), Climate Variability and Extremes during the Past 100 Years. Advances in Global Change Research. Springer Netherlands, pp. 221-233.

Menzel, A., Sparks, T.H., Estrella, N., Koch, E., Aasa, A., Ahas, R., Alm-Kubler, K., Bissolli, P., Braslavska, O., Briede, A., Chmielewski, F.M., Crepinsek, Z., Curnel, Y., Dahl, A., Defila, C., Donnelly, A., Filella, Y., Jatcza, K., Mage, F., Mestre, A., Nordli, O., Penuelas, J., Pirinen, P., Remisova, V., Scheifinger, H., Striz, M., Susnik, A., Van Vliet, A.J.H., Wielgolaski, F.E., Zach, S. and Zust, A., 2006. European phenological response to climate change matches the warming pattern. Global Change Biology, 12(10): 1969-1976. doi: 10.1111/j.1365-2486.2006.01193.x

Murray, M.B., Cannell, M.G.R. and Smith, R.I., 1989. Date of budburst of 15 tree species in Britain following climatic warming. Journal of Applied Ecology, 26(2): 693-700. doi: $10.2307 / 2404093$

Okie, W.R. and Blackburn, B., 2011. Increasing chilling reduces heat requirement for floral budbreak in peach. Hortscience, 46(2): 245-252.

Parmesan, C., 2007. Influences of species, latitudes and methodologies on estimates of phenological response to global warming. Global Change Biology, 13(9): 1860-1872. doi: 10.1111/j.13652486.2007.01404.x 
Parmesan, C. and Yohe, G., 2003. A globally coherent fingerprint of climate change impacts across natural systems. Nature, 421(6918): 37-42. doi: 10.1038/nature01286

Pope, K.S., Da Silva, D., Brown, P.H. and DeJong, T.M., 2014. A biologically based approach to modeling spring phenology in temperate deciduous trees. Agricultural and Forest Meteorology, 198-199: 15-23. doi: 10.1016/j.agrformet.2014.07.009

Roberts, A.M.I., Tansey, C., Smithers, R.J. and Phillimore, A.B., 2015. Predicting a change in the order of spring phenology in temperate forests. Global Change Biology, 21(7): 2603-2611. doi: 10.1111/gcb.12896

Root, T.L., Price, J.T., Hall, K.R., Schneider, S.H., Rosenzweig, C. and Pounds, J.A., 2003. Fingerprints of global warming on wild animals and plants. Nature, 421(6918): 57-60. doi: $10.1038 /$ nature01333

Ruiz, D., Campoy, J.A. and Egea, J., 2007. Chilling and heat requirements of apricot cultivars for flowering. Environmental and Experimental Botany, 61(3): 254-263. doi: 10.1016/j.envexpbot.2007.06.008

Spencer, J.W., 1971. Fourier series representation of the position of the sun. Search, 2(5): 172.

Viti, R., Andreini, L., Ruiz, D., Egea, J., Bartolini, S., lacona, C. and Campoy, J.A., 2010. Effect of climatic conditions on the overcoming of dormancy in apricot flower buds in two Mediterranean areas: Murcia (Spain) and Tuscany (Italy). Scientia Horticulturae, 124(2): 217224. doi: 10.1016/j.scienta.2010.01.001

Wold, S., Sjöström, M. and Eriksson, L., 2001. PLS-regression: a basic tool of chemometrics. Chemometrics and Intelligent Laboratory Systems, 58(2): 109-130. doi: 10.1016/S01697439(01)00155-1

Wolfe, D.W., Schwartz, M.D., Lakso, A.N., Otsuki, Y., Pool, R.M. and Shaulis, N.J., 2005. Climate change and shifts in spring phenology of three horticultural woody perennials in northeastern USA. International Journal of Biometeorology, 49(5): 303-309. doi: $10.1007 / \mathrm{s} 00484-004-0248-9$ 
Yu, H., Luedeling, E. and Xu, J., 2010. Winter and spring warming result in delayed spring phenology on the Tibetan Plateau. Proceedings of the National Academy of Sciences of the United States of America, 107(51): 22151-6. doi: 10.1073/pnas.1012490107

\section{Figure captions}

Fig. 1. Average flowering date of apricots in the UK NFC between 1960 and 2014. Kendall's rank correlation coefficient $(\tau)$ and $p$ value. Julian days are days from $1^{\text {st }}$ January of each year flowering was analysed.

Fig. 2. Results of Partial Least Squares regression analysis for apricot flowering dates in the UK National Fruit Collection, using the Dynamic Model and the GDH Model for quantifying chill and heat accumulation, respectively. Colour bars in the figures indicate VIP above 0.8 , the threshold for considering variables important. Green and red bars represent, besides importance, a positive and negative relationship, respectively, between flowering and daily chilling and heat accumulation. In the lower graphs (chill accumulation and heat accumulation), bars represent the standard deviation of daily chill and heat accumulation, with colours following the same pattern as for the VIP and model coefficients. Shaded areas and dashed lines represent the range in flowering dates and average flowering date, respectively. GDH stands for Growing Degree Hours; CP for Chill Portions; VIP for variable importance in the projection.

Fig. 3. Response of the average flowering date of apricot to average temperatures during the chilling and warming periods $\left(27^{\text {th }}\right.$ Sep to $26^{\text {th }}$ Feb and $31^{\text {st }}$ Dec to $12^{\text {th }} \mathrm{Apr}$, respectively $(\mathrm{A})$; and response of flowering dates to chill accumulation during the chilling period and heat accumulation during the warming period (B). Colours and contour lines represent predicted flowering dates expressed in 

Julian dates (days of the year) using observed data points of mean apricot flowering dates (black dots). GDH stands for Growing Degree Hours; CP for Chill Portions.

669

670

671

672

Fig. 4. Time trends for mean temperature during the warming period (A), heat accumulation during the warming period (B), completion date of the first $1000 \mathrm{GDH}(\mathrm{C})$, mean temperature during the chilling period (D), chill accumulation during the chilling period $(E)$, completion date of the first $5 \mathrm{CP}$ (F) and completion date of average chill accumulation that enabled heat accumulation (i.e., first 62.7 CP; G). GDH stands for Growing Degree Hours; CP for Chill Portions. Kendall's rank correlation coefficients $(\tau)$ and $p$ values are also shown. Julian days are days from $1^{\text {st }}$ January of each year flowering was analysed.

Fig. 5. Time trend of mean temperature during the 40 days before and after flowering for each season. Kendall's rank correlation coefficient $(\tau)$ and $p$ value are given.

\section{Appendix A. Supplementary information}

Table A.1. Summary of the UK's NFC apricot flowering dates archive.

Fig. A.1. Averages and box plots of the flowering date of apricot varieties in the UK NFC between 1960 and 2014.

Fig A.2. Results of the partial squares regression of the average flowering dates of apricot varieties of the UK using daily mean temperatures as the predictor variable.

Fig A.3. Correlation between the date of completion of the first $5 \mathrm{CP}$ of the season and the heat required for flowering. 
Table A.1. Summary of the UK's NFC apricot flowering dates archive.

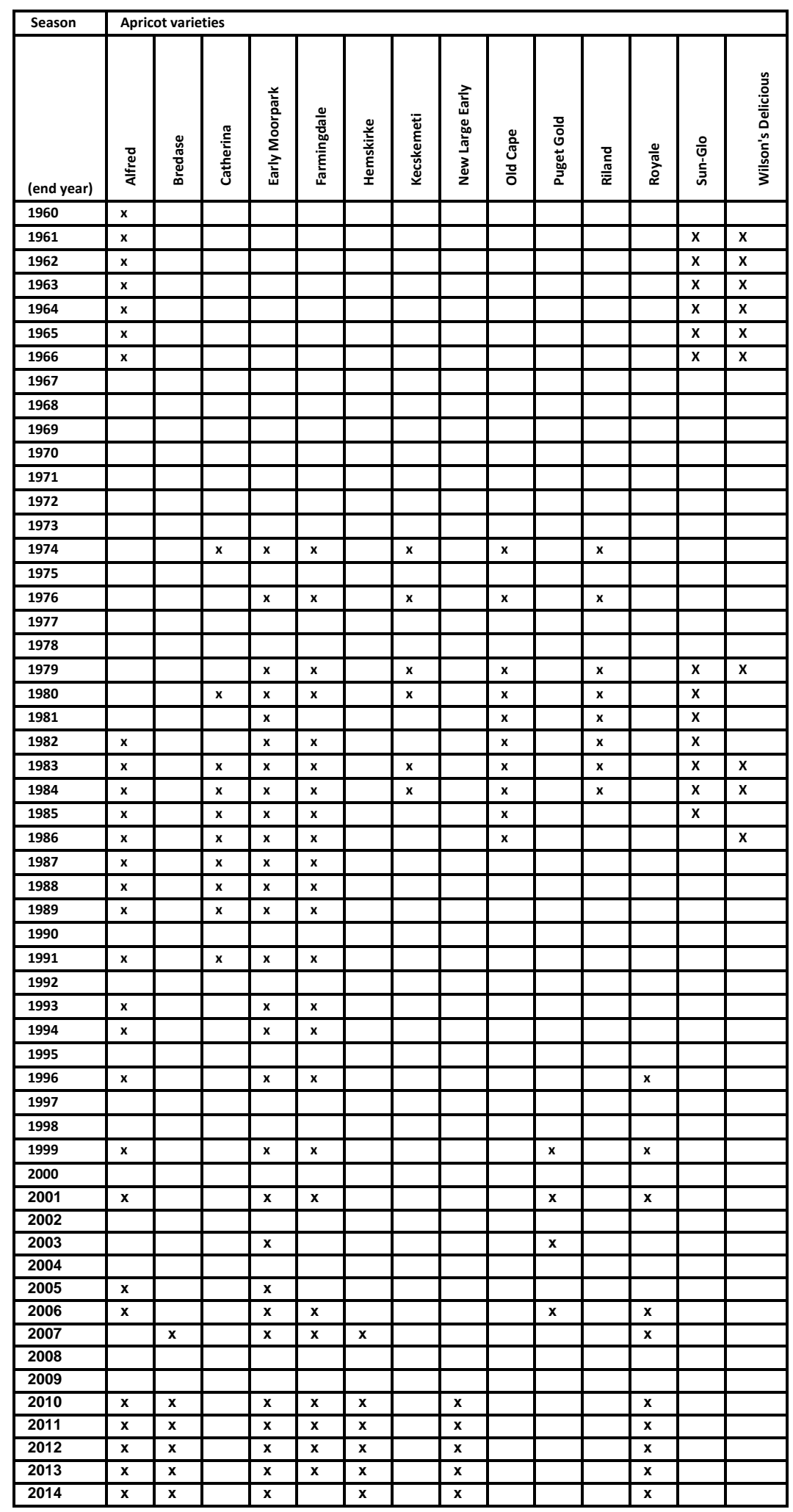




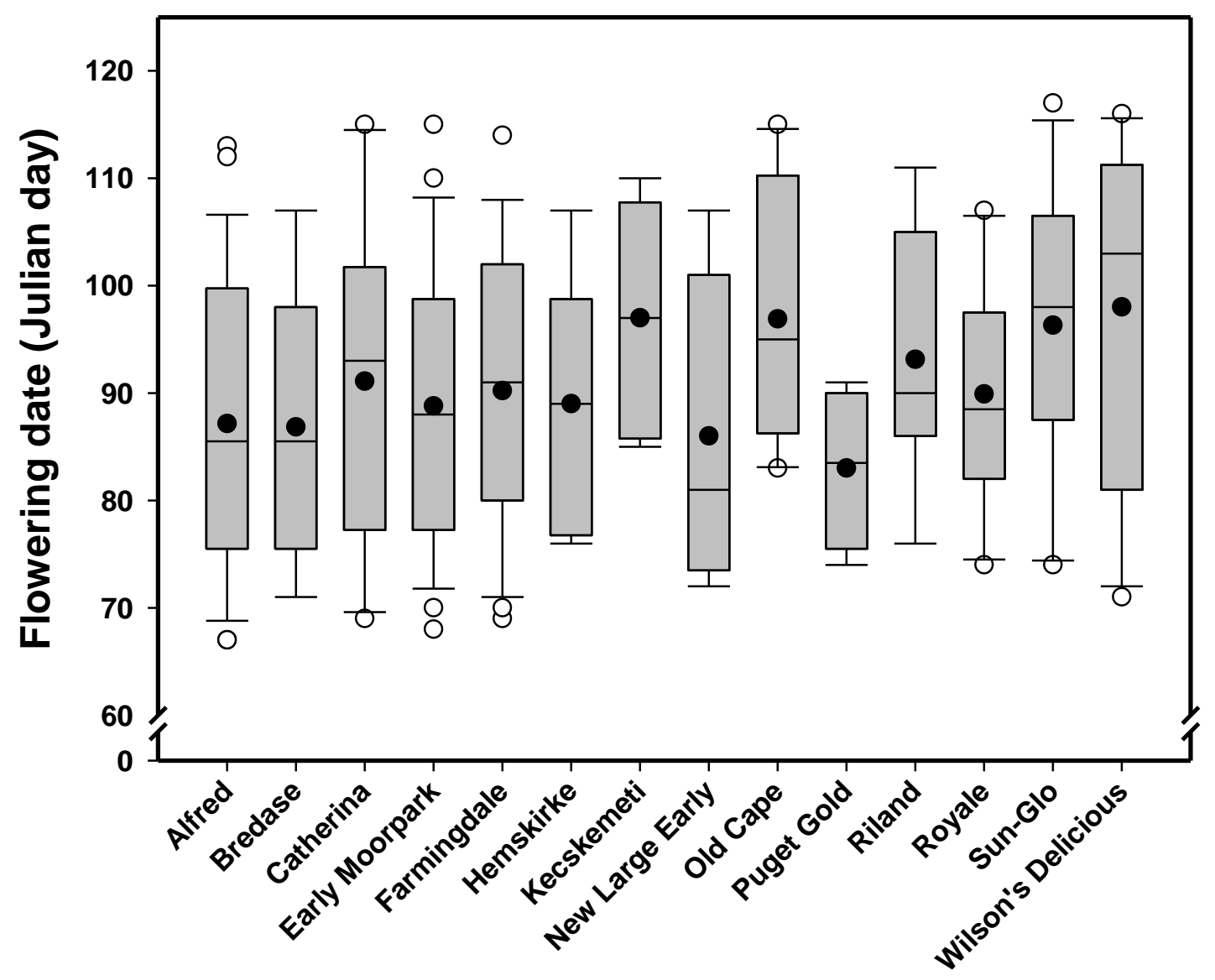

Fig. A.1. Averages (closed circles) and box plots of the flowering date of apricot varieties in the UK NFC between 1960 and 2014. 


\section{VIP}

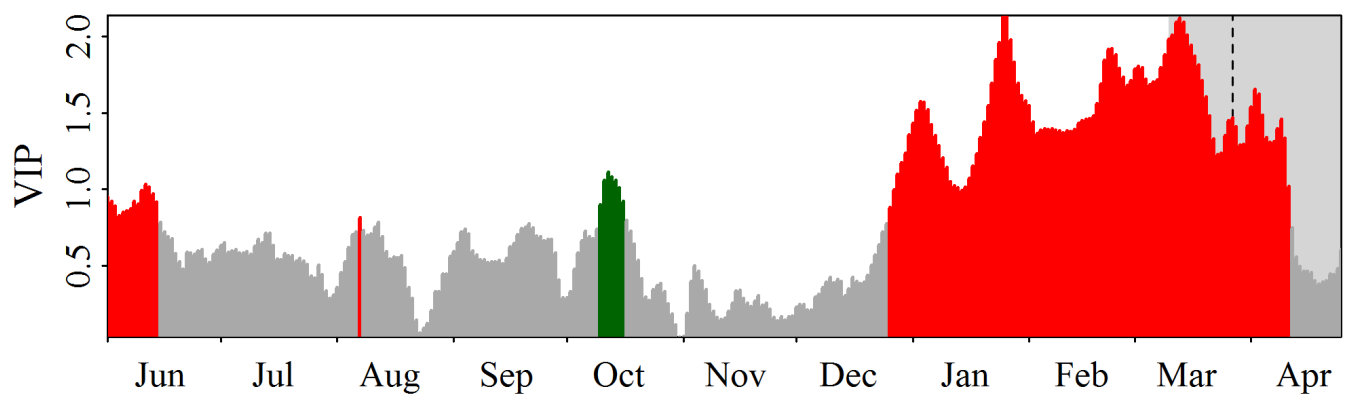

\section{Model coefficients}
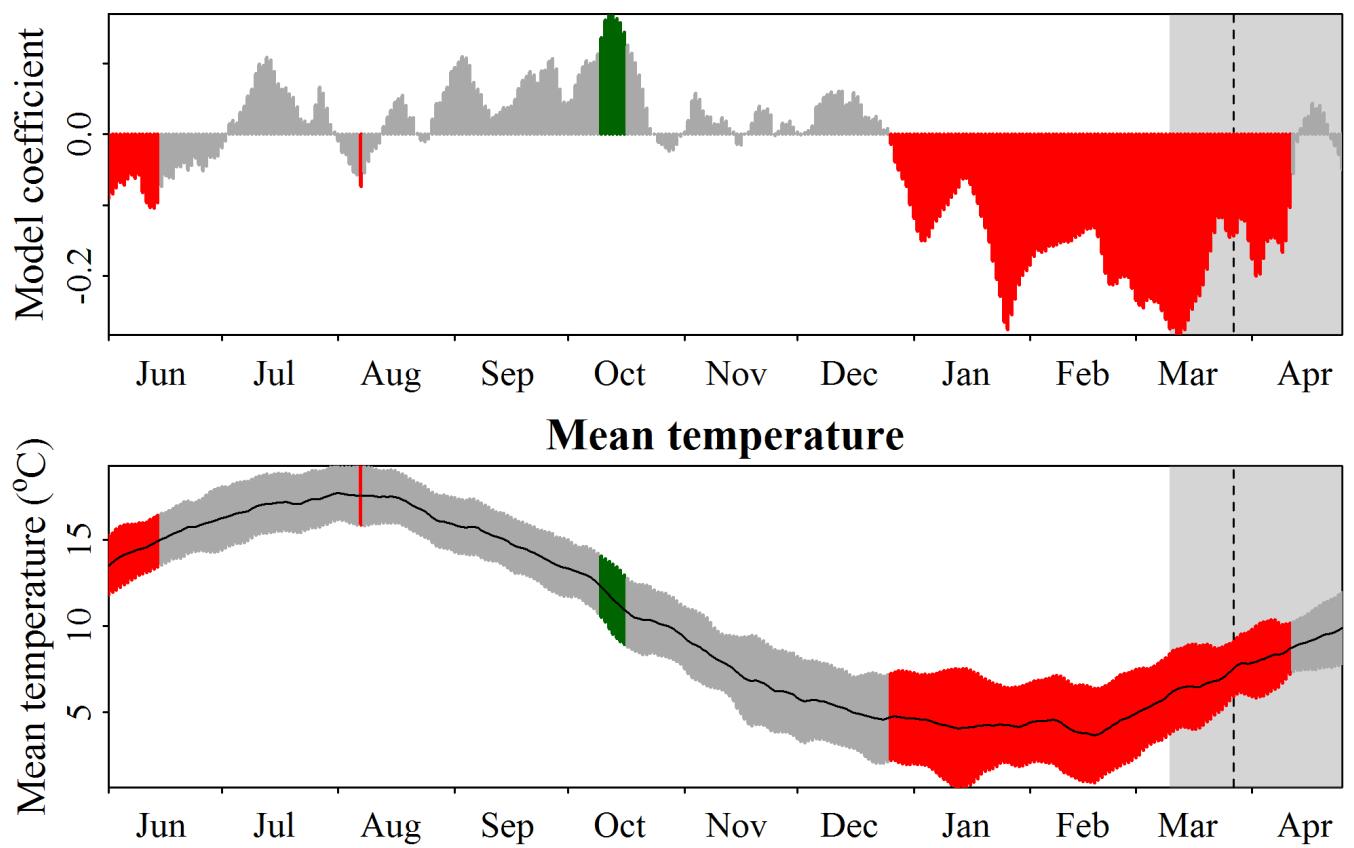

Figure A.2. Results of the PLS regression of the average flowering dates of apricot varieties of the UK using daily mean temperatures as the predictor variable. Colour bars in the figures indicate VIP above 0.8 , the threshold for considering variables important. Green and red bars represent, besides importance, a positive and negative relationship, respectively, between flowering and temperatures. In the lower graphs (Mean temperature), bars represent the standard deviation of mean temperatures, with colours following the same pattern as for the VIP and model coefficients. Shaded areas and dashed lines represent the range in flowering dates and average flowering date, respectively. VIP stands for variable importance in the projection. Methods described in Luedeling et al., (2013). 


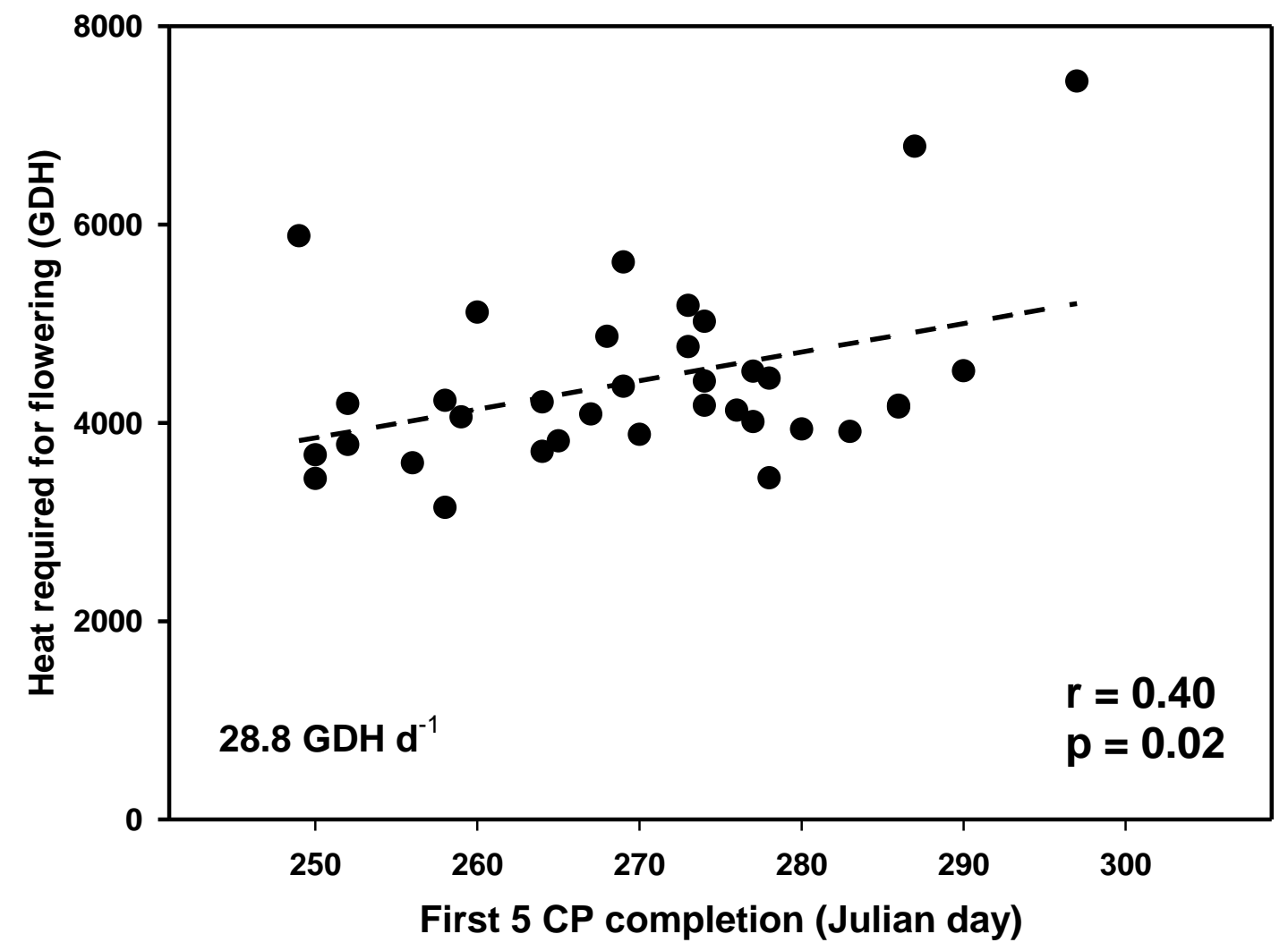

Figure A.3. Correlation between the date of completion of the first $5 \mathrm{CP}$ of the season (starting the $1^{\text {st }}$ July) and the heat required for flowering (GDH from onset of warming period to flowering) showing an increase in $28.8 \mathrm{GDH}$ for each day the accumulation of chilling was delayed. GDH stands for Growing Degree Hours; CP for Chill Portions. 
Figure 1

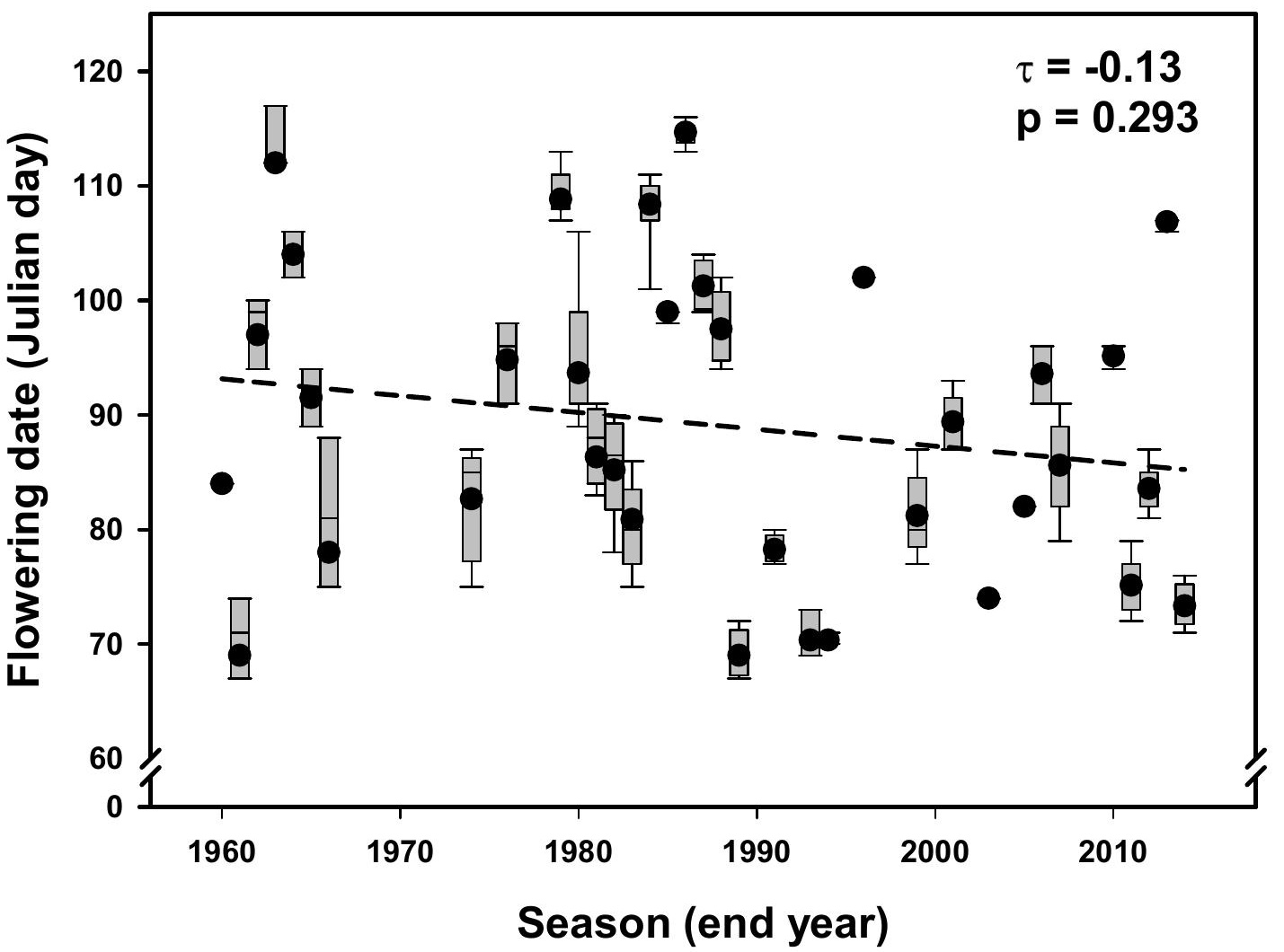




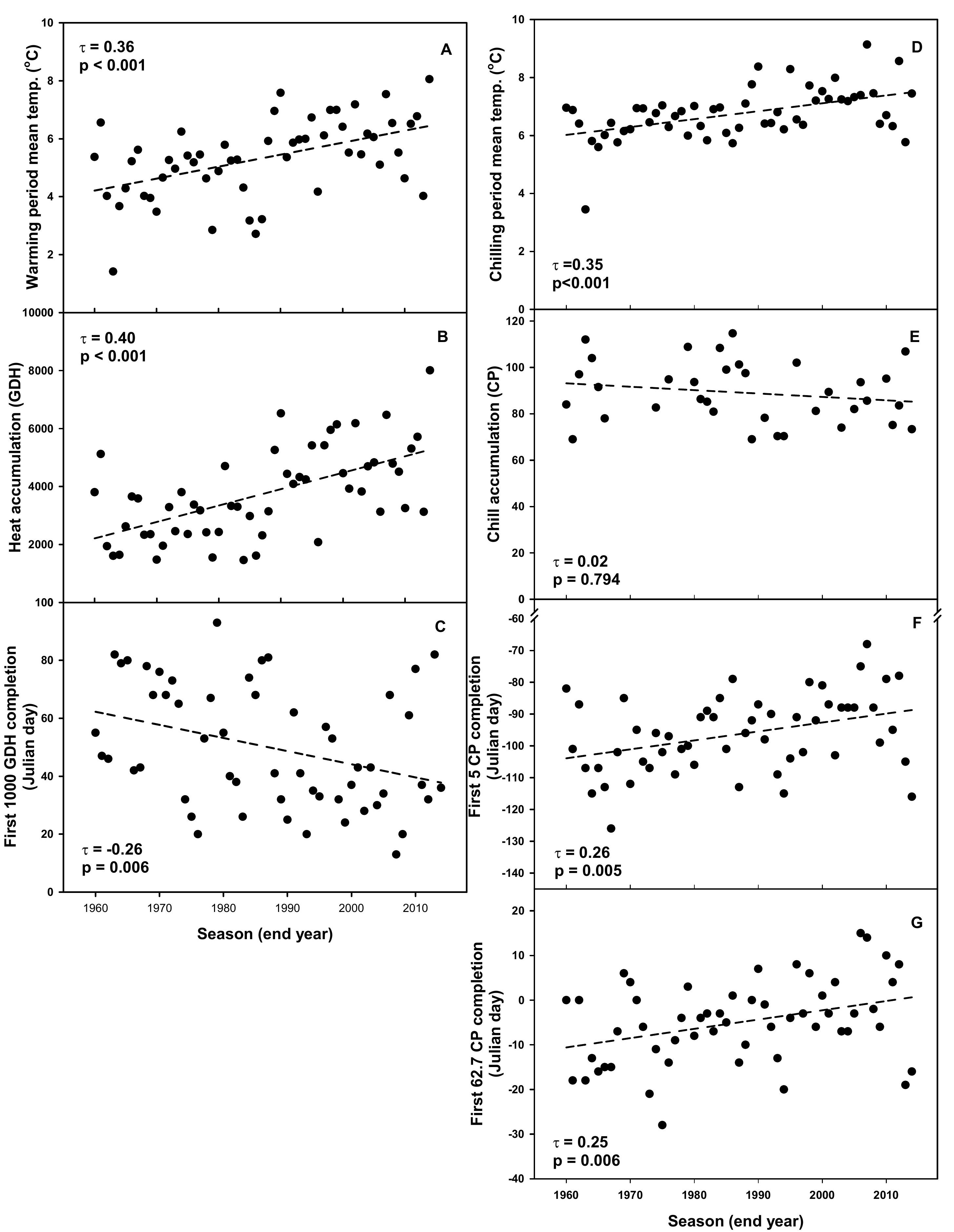


Figure 5

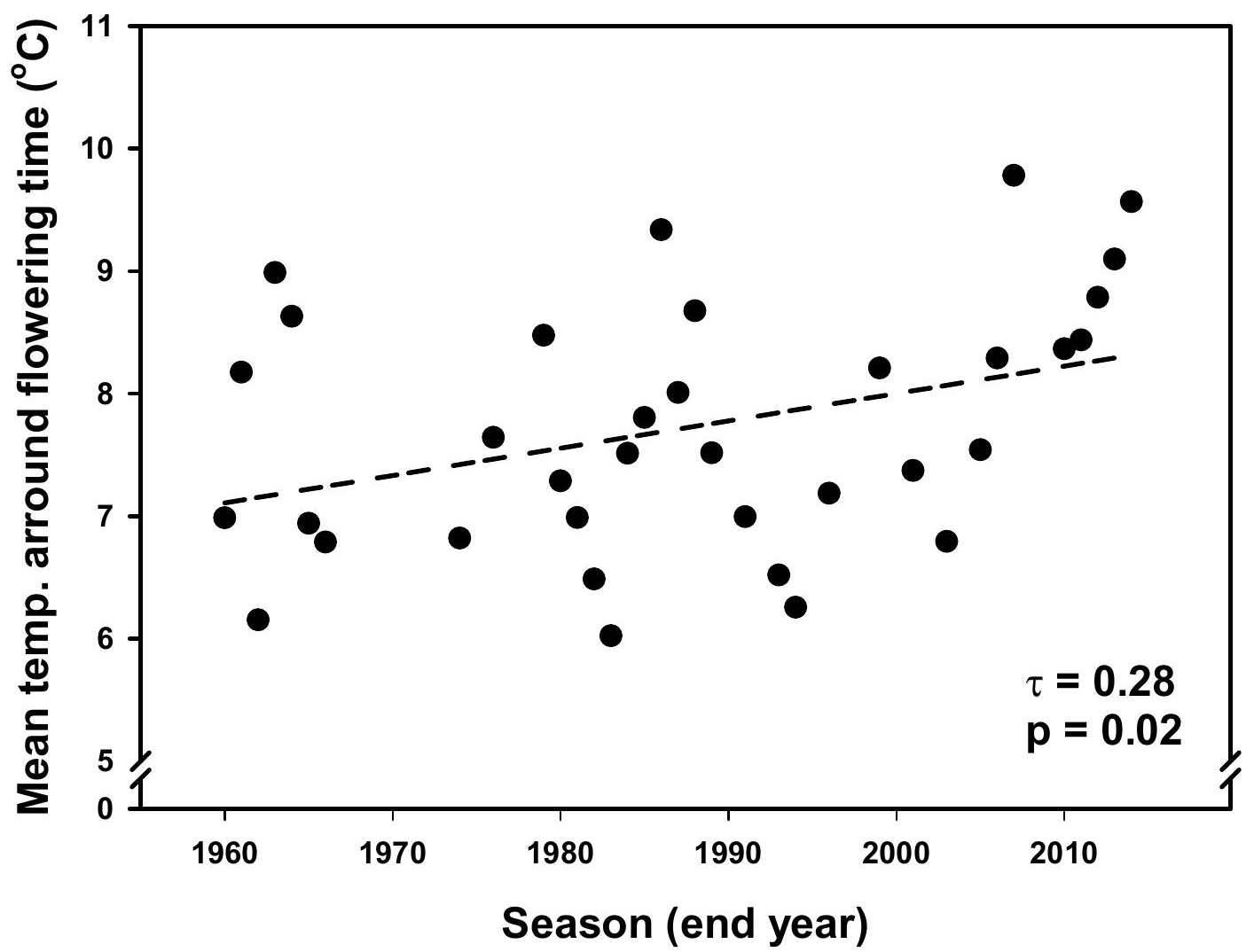

